\title{
HEALTH RELATED QUALITY OF LIFE AMONG PATIENTS WITH BRAIN TUMORS \\ ${ }^{1}$ Amany El Sayed Mohamed Amer, ${ }^{2}$ Amany Mohamed Shebl, ${ }^{3}$ Hanan Mohamed Mohamed Soilman \\ 1,2,3 Medical Surgical Nursing, Faculty of Nursing, Mansoura University E-mail of the corresponding author: amany amer00@, yahoo.com
}

\begin{abstract}
:
Background: Brain tumors are often deadly, impact quality of life, and change everything for patients and their loved ones.. Therefore, measuring quality of life in those patient is important especially as Patients with primary brain tumors face serious challenges to their QOL. The aim of the present study was to assess health related quality of life among patients with brain tumor. Methods: Descriptive study design was used. It was conducted at outpatient clinic of neurology at Mansoura University Hospital, Egypt Sociodemographic sheet was developed and tested by the researcher after extensive review of related literature, it was written in simple Arabic language and covered patient's age, sex, marital status, level of education, occupation, residence and income, past and present history; It was comprised of questions about past and present medical history, previous hospitalization, previous surgery, family health history ,Tool II, The Functional Assessment of Cancer Therapy-General (FACT-G) Scale, it was used to assess patient's own quality of life. Results: The studied subjects age was ranged between 19-60 years, the majority of subjects were female \&about $(98 \% 0)$ have weak income; about $92 \%$ of subjects have no previous cancer, Conclusion: regular assess HRQOL in neuro-oncology practice may improve quality of care by facilitating doctor- patient communication and patient participation in treatment decisions at every stage of the disease. Recommendation: The pattern of HRQOL assessment may serve as an easy and cost-effective tool to recognize early changes in the subjective clinical condition of brain tumor patients, and the relationship with disease progression and helpful in evaluating cancer care outcomes and also have been recently evaluated as early independent predictors of survival
\end{abstract}

Key words: Health Related, Brain Tumor, Quality Of Life.

\section{Introduction:}

Systematic assessment of cognitive function and quality of life needs to be incorporated into clinical trials to determine how different treatment regimens affect these parameters, especially because current treatments are likely to have a limited effect on the length of survival ${ }^{[1]}$. Living with a brain tumor can be very challenging for everyone involved, regardless of the type or severity of the tumor. Being aware of the early signs of mental health problems is important so that those affected can get the right treatment ${ }^{[2]}$. Quality of life of brain cancer patients is often limited. A better understanding of the emotional distress experienced by brain tumor patients could lead to more effective interventions, 
thereby enhancing the ability of patients and families to cope with the illness and enjoy a better quality of life (QOL) ${ }^{[3]}$. It is estimated that 22,020 patients are diagnosed annually with brain cancer in the United States, although brain cancer is relatively rare, it is a disease with serious symptoms and a poor prognosis ${ }^{[4] .}$ Healthrelated of life measures (instruments, questionnaires) were defined as wellestablished questionnaires that measure individuals' perceptions of their own physical, mental and social health status, or some aspects of their health status resulting from cancer and its treatment ${ }^{[5]}$. Quality of life can also be affected by some other illnesses connected to the diagnosis and treatment of brain tumors, including depression and anxiety disorders. In turn, depression and anxiety disorders make it more difficult to adjust to the diagnosis and cope with the changes associated with having a brain tumor.

Enhancing the quality of life of people with brain tumors requires access to quality specialty care, clinical trials, follow-up care, and rehabilitative services. Improving the outlook for adults and children with brain tumors requires research into the causes of and better treatments for brain tumors ${ }^{[6] .}$ The need of cancer patients can be assessed easily and accurately using patient-reported health instruments (PHIs). Measurement of Health Related Quality of Life (HRQL) in brain tumor patients is important because brain tumors and brain tumor treatment usually affect physical, cognitive as well as emotional functioning. Measurement of HRQL is important for the understanding of disease burden and for the impact of specific tumor treatment. ${ }^{[7] .}$

Patients with a brain tumor may experience intense changes in quality of life due to frequent headaches, anorexia, nausea, seizures and insomnia. These patients can also experience neurological deterioration, such as motor impairment, personality changes, cognitive impairment, aphasia or visual impairment, which have a considerable impact on their quality of life) ${ }^{[8]}$. HRQOL measures may not only be helpful in evaluating cancer care outcomes from the patients' or family cares' perspectives but have also been recently evaluated as early independent predictors of survival ${ }^{[9]}$.

[10]. HRQOL data may have value in daily clinical practice. Routine HRQOL measurements of oncology patients visiting the outpatient department, with information provided to physicians, have been shown to have a positive effect on physician-patient communication. In some patients, these measurements improved HRQOL and emotional functioning. However, measurement of HRQOL, symptoms, and functioning is still far from being implemented in daily practice.

There are over 120 different types of brain tumors. In most cases, a brain tumor is named for the cell type of origin. Some brain tumors are named according to their location. Today, most medical institutions use the World Health Organization (WHO) classification system to identify brain tumors. The WHO classification, which is used throughout this guide, classifies brain tumors by cell origin and how the cells behave, from the least aggressive (benign) to the most aggressive (malignant). Some tumor types are assigned a grade, which signifies the rate of growth. There are variations in grading systems, depending on the tumor type. The classification and grade of an individual tumor help predict its likely behavior ${ }^{\text {[11]. }}$

HRQOL has become an important endpoint in cancer studies and has been included in several trials as an outcome measure supplementing other traditional survival end points (overall survival and progression-free survival) ${ }^{[13]}$.

The assessment of patient-reported outcomes in clinical trials and in clinical practice is likely to become a standard part 
of clinical management of brain tumor patients. HRQOL has been reported to have a positive relationship with survival duration

but, at present, there is no definitive evidence that baseline HRQOL scores have additional value with respect to clinical factors for predicting survival. However, considering their limited survival, the HRQOL assessment in patients with brain tumors is particularly important. It is increasingly recognized that the choice of treatment should also involve careful consideration of its effects on the health-related quality of life (HRQOL) during the remaining survival time. ${ }^{[14]}$.

Significance of the study:

Health-related quality of life and survival are two important outcome measures in cancer research and practice. A brain tumor and the treatment necessary to deal with it will cause significant changes in the lives of those affected. The assessment of patient-reported outcomes in clinical trials and in clinical practice is likely to become a standard part of clinical management of BT patients. HRQOL has been reported to have a positive relationship with survival duration ${ }^{[15]}$. The pattern of HRQOL may serve as an easy and cost-effective tool to recognize early changes in the subjective clinical condition of brain tumor patients, and the relationship with disease progression. Moreover, regular assess HRQOL in neuro-oncology practice may improve quality of care by facilitating doctorpatient communication and patient participation in treatment decisions at every stage of the disease. ${ }^{[\mathbf{1 6}] \text {. }}$

Aims of study: The study aim were to:

1- Assess health related quality of life among brain tumor patients .

\section{Subjects and Method:-}

Study Design:-

Descriptive design was used in this study.

\section{Setting:-}

This study was conducted at outpatient clinic of Neurology at Mansoura University Hospital, Egypt.

\section{Subjects:}

A convenient sample of 50 brain tumor patients were included in the study according to the following inclusion criteria: Adult over 18 years old Both sex; (male female) and Willing to participate in the study.

\section{Tools:}

1. An assessment sheet; contained:

a-Socio-demographic sheet which developed by the researcher, it was written in simple Arabic language and covered patient's age, sex, marital status, level of education, occupation, residence and income

b- ( Past and present medical history):

It was comprised of questions about past and present medical history, previous hospitalization, previous surgery, family health history

2. The Functional Assessment of Cancer Therapy-General (FACT-G) Scale) This scale was developed by (Cella and colleagues, 1993), it was used to assess patient's own quality of life and has been modified in brain tumor patients in the FACT-Br.(Weitzner MA, Meyers CA,1995) also patients completed a brain tumor specific sub scale, which together with FACT-general forms the FACTbrain(FACT-BR) it contain 28 item questionnaire with four dimension of HRQL which are Physical condition; physical symptoms regarding headache, seizure, drowsiness, weakness, itching, hair loss social / family condition, emotional condition and functional well being.

\section{Technique :}

- The researchers met the authorized health care providers (physicians and nurses) in the study setting, explained the study aims, and methodology of data collection. 
- As soon as the study idea agreement was obtained, and The researcher started by introducing herself to the study subjects. Clarification of the nature and purpose of the study were done.

- Patient's verbal consent to participate in this study was obtained after explanation of the purpose of the study.

- each patient was Interviewed individually at the outpatient's clinic, in large room, where they were waiting for follow up and other therapeutic measures.

- The researcher assessed quality of life for each patient by utilizing tool II(The Functional Assessment of Cancer Therapy-General (FACT-G) Scale) at different intervals at Neurological clinics and department.

\section{Validity and reliability:}

- An Expert Panel composed of five expertise (three professors nurses and two physician), with their specialty in neurosurgery, and nursing including the head of the neurology outpatient clinics provided scientific oversight and direction for all aspects of the study content validity.

- The expertises reviewed the tools for clarity, relevance, comprehensiveness, understanding, applicability and simplicity for implementation and according to their opinion some modifications were applied.

- On completion of the research plan, data collection took its place under Panel supervision and continuous evaluation of the outcomes.

- Face validity verifies that, the instrument looked like, it was valid or gave the appearance of measuring the content desired for a study, and while contentrelated validity examines the extent to which the method of measurement includes all major elements relevant to the construct being measured.

\section{Pilot study :}

- A pilot study was carried out on five brain tumor patient $(10 \%$ of the study sample), which were excluded from the subjects. Accordingly, any modification was done to improve the study technique quality and efficiency.

- This aimed to ensure clarity, objectivity, relevance and feasibility as well as to identify any problems associated with administration of the questionnaires.

\section{Ethical consideration}

- Consent from ethical committee of faculty of nursing mansoura university prior to start the study.

- An official permission to conduct the study was directed from the Dean of Faculty of Nursing, El-Mansoura University and the director of the university hospital as well as outpatient head nurse, after permission of approval ethical committee .Tools are developed.

- Each patient was reassured that any information obtained would be confidential and would only be used for the study purpose

- Each patient was assured through confidentiality of the data. Patients were also informed that refusal to participate in the study wouldn't affect their care.

\section{Data analysis :}

Data analysis and presentation were represented as descriptive results in the form of frequency and percentage and mean and standard deviation.

Results:

Table 1: shows the general characteristics of the study population. In relation to age, it can be observed that participant' age ranged from 18 to 60 years),Regarding sex, more than half patient were female $(62 \%)$, however the majority of patient were married $(60 \%)$, as regard educational level it was noticed that the majority of studied patient were read\& write $(74 \%)$ 
HEALTH RELATED QUALITY OF LIFE AMONG etc...

and more than half $(52 \%)$ of patient were middle education.

Table (1): General characteristics of the study population $(\mathrm{n}=50)$

\begin{tabular}{|l|l|l|}
\hline \multicolumn{1}{|c|}{ Characteristics } & (N=50) & \% \\
\hline Gender: & 19 & 38 \\
Male & 31 & 62 \\
\hline$\frac{\text { Age }}{18}$ & 11 & 22 \\
40 & 20 & 40 \\
60 & 19 & 38 \\
\hline Marital status & & \\
Single & 4 & 8 \\
Married & 30 & 60 \\
Divorced & 10 & 20 \\
Widowed & 6 & 12 \\
\hline Education & & \\
Illiterate & 18 & 36 \\
Read \&write & 17 & 74 \\
Middle education & 13 & 52 \\
University & 12 & 48 \\
\hline
\end{tabular}

Table (2): Distribution of social data of study patients $(\mathrm{n}=50)$

\begin{tabular}{|l|c|c|}
\hline \multicolumn{1}{|c|}{ Characteristics } & (N=50) & \% \\
\hline Job: & 14 & 56 \\
Employee & 7 & 28 \\
Handcraft & 4 & 16 \\
Farmer & 16 & 64 \\
Housewife & 5 & 20 \\
Retired & 4 & 16 \\
Student & & \\
\hline Income & 5 & 20 \\
Good & 22 & 98 \\
Weak & 10 & 40 \\
\hline Family size & 17 & 68 \\
None & 16 & 28 \\
3 & 8 & 32 \\
4 & & \\
$5+$ & 18 & 72 \\
\hline Self care at home & 32 & 38 \\
\hline Yes & & \\
No & 38 & 52 \\
\hline Sibling & 12 & 48 \\
\hline Yes & & \\
No & & \\
\hline
\end{tabular}

Table 3:Distribution of past medical \& family history history

\begin{tabular}{|l|c|c|}
\hline \multicolumn{1}{|c|}{ Characteristics } & (N=50) & \% \\
\hline Duration of cancer & 18 & 36 \\
< I year & 21 & 42 \\
$1-3$ & 11 & 22 \\
$4+$ & & \\
\hline Site of previous & & \\
cancer & 46 & 92 \\
No & 2 & 4 \\
Chest & 1 & 2 \\
Prostate & 16 & 32 \\
Relative with cancer & & \\
Yes & 34 & 68 \\
No & & \\
\hline Relative relation & 2 & 4 \\
Uncle son & 1 & 2 \\
Aunt husband & 3 & 6 \\
Aunt & 5 & 1 \\
Brother & 1 & 2 \\
Uncle & 2 & 4 \\
Sister & 1 & 2 \\
Mother & 1 & 2 \\
Grandmother & \\
\hline
\end{tabular}

Table 2: Regarding job, it was noticed that the majority of subject were housewife $(64.0 \%)$, there was no statistically significant $\quad(p=0.627)$,In relation to income: The majority of patients were having weak income (98\%) Regarding family size: The majority of patients $(68 \%)$ have (3) children about $(72 \%)$ of subjects were self care at home, otherwise only $38 \%$ of patients were not

Table3: Regarding duration of cancer less than half studied subject their duration was in between 1-3 years $(42.0 \%)$ and about $(36.0 \%)$ their duration was less than one year, there were no statistically significant In relation to site of previous cancer no one in patient had previous cancer $(92.0 \%)$, while only $(4.0 \%)$ has chest cancer with no statistically significant Regarding relative relation with subject it was noticed that the majority of subject were aunt relation (6. \%)

Table4 : Patients' overall quality of life was clinically significantly increased 
Amany El Sayed Mohamed Amer l et. al.

specifically social/ family wellbeing and emotional wellbeing were more domain statistically significant than other quality of domain physical and functional wellbeing subscales with $p$ value (0.007\&0.003)respectively

Table 4: Describition of QOL domain in brain tumor patients

\begin{tabular}{|l|c|c|c|}
\hline \multicolumn{1}{|c|}{ Quality of life Domain } & Mean scores & \pm SD & p value \\
\hline Physical Well-Being & 18.5 & $(6.4)$ & $\mathrm{p}=0.18$ \\
\hline Social/Family Well-Being & 20.1 & $(6.3)$ & $\mathrm{p}=0.007$ \\
\hline Psychological Well-Being & 16.7 & $(5.1)$ & $\mathrm{p}=0.003$ \\
\hline Functional Well-Being & 17.9 & $(6.7)$ & $\mathrm{p}=0.15$ \\
\hline Total QOL score & 61.7 & $(17.3)$ & $\mathrm{p}=0.003$ \\
\hline
\end{tabular}

Table (5): Relation between quality of life and subjects socio-demographic characteristics.

\begin{tabular}{|c|c|c|c|c|c|c|}
\hline \multirow{3}{*}{ Variables } & \multicolumn{4}{|c|}{ Quality of life } & \multirow{3}{*}{$\mathrm{X} 2$} & \multirow{3}{*}{ P-Value } \\
\hline & \multicolumn{2}{|c|}{ Satisfactory } & \multicolumn{2}{|c|}{ Unsatisfactory } & & \\
\hline & no & $\%$ & No & $\%$ & & \\
\hline $\begin{array}{l}\text { Age (years) } \\
30 \mathrm{y} \\
30-40 \mathrm{y} \\
40-50 \mathrm{y} \\
50 \mathrm{y}\end{array}$ & $\begin{array}{l}1 \\
0 \\
0 \\
0 \\
\end{array}$ & $\begin{array}{c}100.0 \% \\
0 \% \\
.0 \% \\
0 \%\end{array}$ & $\begin{array}{c}3 \\
13 \\
21 \\
12\end{array}$ & $\begin{array}{l}6.1 \% \\
26.5 \% \\
42.9 \% \\
24.5 \% \\
\end{array}$ & 11.7 & .004 \\
\hline $\begin{array}{l}\text { Gender } \\
\text { Male } \\
\text { Female }\end{array}$ & $\begin{array}{l}1 \\
0\end{array}$ & $\begin{array}{c}100.0 \% \\
0 \%\end{array}$ & $\begin{array}{l}23 \\
26\end{array}$ & $\begin{array}{l}46.9 \% \\
53.1 \%\end{array}$ & 1.10 & .29 \\
\hline $\begin{array}{l}\text { Treatment } \\
\text { Chemical } \\
\text { Radiation Chemical } \\
\text { Surgical } \\
\text { Surgical Chemical } \\
\text { Radiation Surgical }\end{array}$ & $\begin{array}{l}0 \\
0 \\
1 \\
0 \\
0\end{array}$ & $\begin{array}{c}0 \% \\
0 \% \\
100.0 \% \\
0 \% \\
0 \%\end{array}$ & $\begin{array}{c}6 \\
4 \\
16 \\
17 \\
6\end{array}$ & $\begin{array}{c}12.2 \% \\
8.2 \% \\
32.7 \% \\
34.7 \% \\
12.2 \%\end{array}$ & 1.98 & .73 \\
\hline $\begin{array}{l}\text { Residence } \\
\text { Rural } \\
\text { Urban }\end{array}$ & $\begin{array}{l}0 \\
1\end{array}$ & $\begin{array}{c}0 \% \\
100.0 \%\end{array}$ & $\begin{array}{l}28 \\
21\end{array}$ & $\begin{array}{l}57.1 \% \\
42.9 \%\end{array}$ & 1.29 & .254 \\
\hline $\begin{array}{l}\text { Marital Status } \\
\text { Single } \\
\text { Married } \\
\text { Divorced } \\
\text { Widow }\end{array}$ & $\begin{array}{l}1 \\
0 \\
0 \\
0\end{array}$ & $\begin{array}{c}100.0 \% \\
0 \% \\
0 \% \\
0 \%\end{array}$ & $\begin{array}{c}3 \\
41 \\
3 \\
2 \\
\end{array}$ & $\begin{array}{c}6.1 \% \\
83.7 \% \\
6.1 \% \\
4.1 \% \\
\end{array}$ & 11.73 & .008 \\
\hline $\begin{array}{l}\text { Education } \\
\text { Illiterate } \\
\text { Read \&Write } \\
\text { Primary } \\
\text { Secondary } \\
\text { High } \\
\text { University }\end{array}$ & $\begin{array}{l}0 \\
0 \\
0 \\
0 \\
0 \\
1\end{array}$ & $\begin{array}{c}0 \% \\
0 \% \\
0 \% \\
0 \% \\
0 \% \\
100.0 \%\end{array}$ & $\begin{array}{c}5 \\
1 \\
7 \\
22 \\
4 \\
10\end{array}$ & $\begin{array}{l}10.2 \% \\
2.0 \% \\
14.3 \% \\
44.9 \% \\
8.2 \% \\
20.4 \%\end{array}$ & 3.6 & .606 \\
\hline $\begin{array}{l}\text { Occupation } \\
\text { Employee } \\
\text { Worker } \\
\text { Farmer } \\
\text { Housewife } \\
\text { Student }\end{array}$ & $\begin{array}{l}0 \\
0 \\
0 \\
0 \\
1\end{array}$ & $\begin{array}{c}0 \% \\
0 \% \\
0 \% \\
0 \% \\
100.0 \%\end{array}$ & $\begin{array}{c}31 \\
2 \\
4 \\
12 \\
0\end{array}$ & $\begin{array}{c}63.3 \% \\
4.1 \% \\
8.2 \% \\
245 \% \\
0 \%\end{array}$ & 50.0 & .000 \\
\hline $\begin{array}{l}\text { Income } \\
\text { Enough } \\
\text { Not enough }\end{array}$ & $\begin{array}{l}0 \\
1\end{array}$ & $\begin{array}{r}0 \% \\
100.0 \%\end{array}$ & $\begin{array}{l}10 \\
39\end{array}$ & $\begin{array}{l}20.4 \% \\
79.6 \%\end{array}$ & .255 & .61 \\
\hline
\end{tabular}




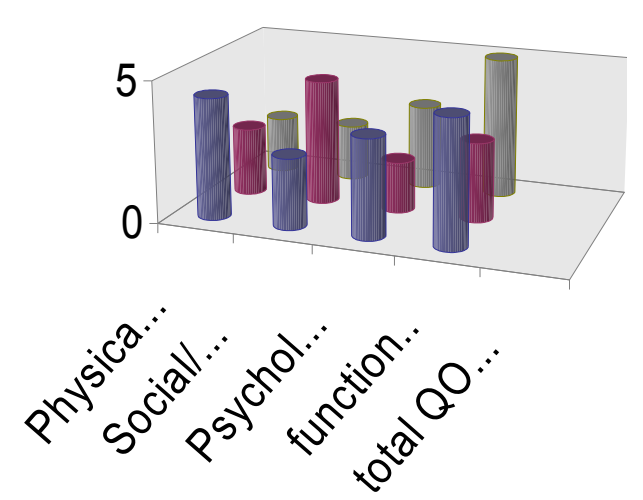

Table5: Relation between quality of life and socio- demographic characteristics, it was clear that there was statistically significant relation regarding age with $\mathrm{p}$ value $\mathrm{p}=, 004$, also there was significant relation between marital status, and with occupation with $p$ value $p=.000$

\section{Discussion:}

Brain tumors are frequently a significant cause of morbidity to patients and their families. Mortality is high and generally occurs within a few years, and often there is an expectation that patients undergoing treatment for cancer will experience a decline in function and / or quality of life due to either their underlying disease process and /or the side effects from treatment ${ }^{[17]}$. Quality of life is an area of study that has attracted an ever increasing amount of interest over the past two decades, particularly in the areas of health, rehabilitation, disabilities, and social services, nevertheless in medicine education.

The findings of the present study revealed that, more than half of study patients were among age between 18 to 60 years old, this findings was in agreement with American Society Of Clinical
Oncology 2010 that reported that most common age for brain tumor is average 55 years Accordingly, the patient usually contaminates the catheter, rather than vice versa ${ }^{[18]}$. Concerning sex, the result of the present study illustrated that the majority of subjects were females (62\%) this was contradicted with American cancer society ,2010 that stated that more than $42.8 \%$ of woman in new York state age diagnosed with cancer of brain and nervous system, [19\&20]. Regarding marital status, the current study revealed that the more than half $(60 \%)$ of subjects were married . this finding was contradicted with Helina Hakko,2008 that also reported that about two thirds of patients was married ${ }^{[21]}$.

Regarding income, the present study revealed that the majority of subjects were having weak income this finding was contradicted with Central Brain Tumor Registry at United States ,2013 who reported that brain cancer carriers the highest income individual have brain tumor.

Regarding quality of life domain specifically social / family well being and emotional were assessed as satisfied. However, physical and functional well being were assessed as unsatisfied. This was contradicted with David, etal, 2007 who stated that patients with a brain tumor live with a clinically significant reduction in their overall quality of life compared to the general population. This finding holds true irrespective of the time since diagnosis or the time since last treatment Also Brown PD,etal ,2008 who reported that among a group of newly diagnosed brain tumor patients, quality of life scores (measured by the FACT-Br were found to be predictive of survival.

\section{Conclusion:}

Assessing quality of life domain in these patient help to reduce cost of different treatment options and make follow up easily for patients. 
- HRQOL measures may be helpful in evaluating cancer care outcomes and also have been recently evaluated as early independent predictors of survival.

HRQOL has been reported in several studies but needs to be better defined. Moreover, the HRQOL in advanced disease and during the end-of-life phase of brain tumor patients still remains a neglected issue so Further studies should be conducted on quality of life assessment.

As survival is limited, patients optimally should be informed of the impact of all treatment options on their quality of life at the time of diagnosis. Relatively little is known about HRQOL during the disease course of patients with high-grade gliomas.

\section{Recommendation:}

In the light of the findings of the current study, the following recommendations are suggested:

\section{Administrative:}

Patient's care in the out patient's clinics for brain tumor should be improved in order to offer more comfort and benefits to the patients, which may improve their quality of life.

Since brain tumor is serious disease that accompanies the patient for life, encourage health insurance system.

Increase cooperative efforts between faculty of nursing staff and hospital managers to offer continuous health education to serious disease for all health care providers.

National screening survey should be carried out to detect tumor as early as possible.

\section{Educational:}

For patients:

Continuous health teaching using T.V programs, video tapes, brochures, should be available to make use of their waiting time prior receiving the necessary health services.

\section{For nurses:}

Designing a training program for outpatient nurses about brain tumor and its management, and proper ways to assess QOL. quality of life

- Psychological and social aspects in caring for brain tumor patients should be emphasized and integrated to nursing education.

C. For clinical practice:

- Apply the current research findings to help patient to return to their back function and improve their quality of life.

- Staff should carry out a periodic patient's assessment for brain tumor during their hospitalization.

\section{Acknowledgments:}

I would like to thank all brain tumor patients as well as nurses and the head of neurology outpatient clinics, El-Mansoura University Hospital, as it would not have been possible to complete this work without their valuable contribution, cooperation and support.

\section{References:}

1. Quinten C, Coens C, Mauer M, Comte S, Sprangers MA, Cleeland C, Osoba D, Bjordal K, Bottomley A, EORTC Clinical Groups: Baseline quality of life as a prognostic indicator of survival: a metaanalysis of individual patient data from EORTC clinical trials.

2. Jemal A, Siegel R, Xu J, Ward E: Cancer statistics, 2010. CA: a cancer j clinicians 2010, 60(5):277-300.

3. Coates A, Gebski V, Signorini D, et al. Prognostic value of quality-of-life scores during chemotherapy for advanced breast cancer. Australian New Zealand Breast Cancer Trials Group. J Clin Oncol 1992;10:18331838.

4. Coates A, Thomson D, McLeod GR, et al. Prognostic value of quality of life scores in a trial of chemotherapy with or without interferon in 
HEALTH RELATED QUALITY OF LIFE AMONG etc...

patients with metastatic malignant melanoma. Eur $J$ Cancer 1993;29A:1731-1734

5. Alderman AK, Hawley ST, Waljee J, Mujahid M, Morrow M, Katz SJ. Understanding the impact of breast reconstruction on the surgical decision-making process for breast cancer. Cancer .2008; 112:489-94.

6. Armstrong TS, Cohen MZ, Eriksen LR, Hickey JV. Symptom clusters in oncology patients and implications for symptom research in people with primary brain tumors. $J$ Nurs Sch. 2004;36:197-206. 54. Fox SW, Lyon D,

7. Taphoorn MJ, Stupp R, Coens C, et al. Health-related quality of life in patients with glioblastoma: a randomised controlled trial. Lancet Oncol. 2005; 6:937-944.

8. Mainio A, Hakko H, Niemela A, Koivukangas J, Rasanen P. Depression and functional outcome in patients with brain tumors: a populationbased 1-year follow-up study. J Neurosurg. 2005; 103:841847.

9. E, Anderson F Jr, Meyers CA, Huang W, Laws ER Jr. Depression in patients with high-grade glioma: results of the Glioma Outcomes Project. Neurosurgery. 2004;54:358367

10. Norden AD, Young GS, Setayesh K, Muzikansky A, Klufas R, Ross GL, et al. Bevacizumab for recurrent malignant gliomas: efficacy, toxicity, and patterns of recurrence. Neurology . 2008 Mar 4;70(10):77987.

11. World Health Organization. (1991). Report of the WHO Meeting on the Assessment of Quality of Life in Health Care. Geneva: WHO (MNH/PSF/91.4)

12. Park, Bong Jin; Kim, Han Kyu; Sade, Burak; Lee, Joung H. (2009).
"Epidemiology". In Lee, Joung $\mathrm{H}$. Meningiomas: Diagnosis, Treatment, and Outcome. Springer. p. 11. ISBN 978-1-84882-910-7.

13. Frei, P; Poulsen, AH, Johansen, C, Olsen, JH, Steding-Jessen, M, Schüz, J (19 October 2011). "Use of mobile phones and risk of brain tumours: update of Danish cohort study.". BMJ (Clinical research ed.) 343: d6387. doi:10.1136/bmj.d6387. PMC 3197791. PMID 22016439

14. Pearce NJ, Sanson-Fisher R, Campbell HS (2008) Measuring quality of life in cancer survivors: a methodological review of existing scales. Psycho-Oncology. 17, 7, 629640.

15. Ohgaki H, Kleihues P. Populationbased studies on incidence, survival rates, and genetic alterations in astrocytic and oligodendroglial gliomas. J Neuropathol Exp Neurol 2005; 64:479-489

16. Cheng JX, Zhang X, Liu BL. Healthrelated quality of life in patients with high-grade glioma. Neuro Oncol 2009; 11:41-50.

17. Fallowfield L. Quality of life: a new perspective for cancer patients. Nat Rev Cancer 2002; 2: 873-879

18. US Food and Drug Administration. Guidance for Industry: PatientReported Outcome Measures: Use in Medical Product Development to Support Labeling Claims. www.fda.gov/CDER/GUIDANCE/546 0dft.pdf (last.

19. Functional Assessment of Chronic Illness Therapy. www.facit.org (last accessed 25 February 2009.

20. Montazeri A, Milroy R, Hole D, McEwen J, Gillis CR: How quality of life data contribute to our understanding of cancer patients' experiences? A study of patients with lung cancer. Qual Life Res 2003, 12:157-166 
21. Montazeri A: Health-related quality of life in breast cancer patients: a bibliographic of the literature from 1974 to 2007. J Exp Clin Cancer Res 2008, 27:32.

22. Quinten C, Coens C, Mauer M, Comte S, Sprangers MA, Cleeland C, Osoba D, Bjordal K, Bottomley A, EORTC Clinical Groups: Baseline quality of life as a prognostic indicator of survival: a metaanalysis of individual patient data from EORTC clinical trials. Lancet Oncol 2009, 10:865-871.

23. Buccheri GF, Ferrigno D, Tamburini M, Brunelli C: The patient's perception of his own quality of life might have an adjunctive prognostic significance in lung cancer. Lung Cancer 1995, 12:45-58.

24. Chlebowski RT, Lillington LM. A decade of breast cancer clinical investigations. $J$ Clin Oncol 1994; 12:1789-952.

25. Mackworth N, Forbair $P$, Prados MD: Quality of life selfreports from 200 brain tumor patients: comparisons with Karnofsky performance scores. J Neuro-Oncol 14: 243-253,1999.

26. Langendijk H, Aaronson NK, de Jong JM, ten Velde GP, Muller MJ, Wouters M: The prognostic impact of quality of life assessed with the EORTC QLQ-C30 in inoperable non-small cell lung carcinoma treated with radiotherapy. Radiother Oncol 2000, 55:19-25

27. Ganz PA, Lee JJ, Siau J: Quality of life assessment. An independent prognostic variable for survival in lung cancer. Cancer.
28. Moinpour CM, Lyons B, Grevstad PK, Lovato LC, Growley J, Czaplicki K, Buckner ZM, Ganz PA, Kelly K, Gandara DR: Quality of life in advanced non-small-cell lung cancer: results of a Southwest Oncology Group randomized trial. Qual Life Res 2002, 11:115-126.

29. Jemal A, Siegel R, Xu J, Ward E: Cancer statistics, 2010. CA: a cancer j clinicians 2010, 60(5):277-300.

30. Iran center for disease control and prevention, cancer office: Iranian annual of national cancer registration report 2006-2007. Tehran: Ministry of health;2008

31. Cella DF, Tulsky DS, Gray G, et al: The Functional Assessment of Cancer Therapy Scale: development and validation of the general measure.J oncology: official j Am Soc Clin Oncology 1993, 11(3):570579

32. Osoba D, Aaronson NK, Muller M, et al: The development and psychometric validation of a brain cancer quality-of-life questionnaire for use in combination withgeneral cancer specific questionnaires.Quality of Life Res 1996, 5(1):139-150.

33. Taphoorn MJ, Claassens L, Aaronson, Coens C, Mauer M, Osoba D, Stupp R, EORTC Quality of Life Group, and Brain Cancer, NCIC and Radiotherapy Groups.An international validation study of the EORTC brain cancer module (EORTC QLQ-BN20) for assessing health related quality of life and symptoms in brain cancer patients. Eur J Cancer 2010, 46(6): 1033-1040. 